\title{
Effective Use of MPC for Dynamic Decoupling of MIMO Systems
}

\author{
Pavel Dworak $^{1}$, Jitendra Kumar Goyal ${ }^{2}$, Shubham Aggarwal ${ }^{2}$, Sandip Ghosh ${ }^{2}$ \\ ${ }^{1}$ West Pomeranian University of Technology, \\ 26 Kwietnia 10, 71-126 Szczecin, Poland \\ ${ }^{2}$ Indian Institute of Technology, Banaras Hindu University, \\ Varanasi-221005 (UP), India \\ pawel.dworak@zut.edu.pl
}

\begin{abstract}
The article analyses possible ways of using predictive controllers to perform control tasks and dynamic decoupling for dynamic systems with Multiple Inputs and Multiple Outputs (MIMO). The results of experiments on the selected reference plant are presented, showing the effectiveness of individual decoupling methods. These are also compared to those obtained in typical control systems with Proportional-Integral-Derivative (PID) controllers. Recommendations are made on how to tune model predictive controllers (MPC) for their effective use for MIMO plants.
\end{abstract}

Index Terms-Dynamic decoupling: Model Predictive Controller; Proportional-Integral-Derivative Controller; Multiple Input Multiple Output; Tuning methods.

\section{INTRODUCTION}

Dynamic decoupling of a MIMO (Multiple Inputs and Multiple Outputs) system is a very difficult task to perform in practice. Most often, it boils down to minimization of the coupling effects instead of full decoupling. As control of MIMO dynamic systems enjoys a continuous attention [1], [2], a challenging task becomes to include the dynamic decoupling problem [3]-[14].

In [1], an automatic two-step procedure for tuning of Proportional-Integral-Derivative (PID) controller for a Two Input Two Output (TITO) process is presented. References [6], [7] gives necessary and sufficient conditions for the existence of diagonal, block-diagonal, and triangular decoupling controllers for non-square plants and systems with non-unity feedback, and with one or two degree-offreedom controller configuration. Further, [8] has proposed a condition to check the existence of one-degree-of-freedom block decoupling controller. Parameterization of block decoupling controllers along with solving an $\mathrm{H}_{2}$ optimal problem is proposed in [9]. Reference [10] considers MIMO as proper, lumped, and linear time invariant systems and gives analytical expressions of the Input/Output (I/O) decoupling problem by the use of two-parameter stabilizing control. In [11], a robust decoupling controller for uncertain MIMO systems has been proposed, where uncertainty of model parameters and the desired performance is taken into account, and the min-max non-convex optimization problem is used in the controller design. In [15]-[18], switching, fuzzy, and neural decoupling controllers are constructed in

Manuscript received 20 August, 2018; accepted 2 December, 2018. order to control the nonlinear MIMO systems. Reference [19] presents a survey on decoupling control based on multiple plant models.

In recent years, technological development has increased the possibility of using predictive controllers. They seem to be ideally suited to deal with MIMO plants. Thus, we can find some works on dynamic decoupling with the use of MPC [20]-[28]. Most of them have been created for specific TITO nonlinear plants [21], [23], [25]-[27]. However, as we see in these works, the MIMO predictive controller does not automatically solve decoupling. In [21], [25]-[27] to obtain dynamic decoupling effects the MPC algorithm decelerates the change in reference signals and is changing the error weighting factors in the MPC cost function. [23] shows fuzzy, predictive, and functional control with the control law given in an analytical form.

MPC with the classical control schemes are compared in this paper to show that it allows us to obtain much better results when a dynamic decoupling comes into effect. It is further illustrated that the predictive controller does not decouple plants automatically and, therefore, some tuning methods are necessary to obtain the dynamic decoupling effect. Additionally, we analyse the pros and cons of different tuning methods of the MPC algorithm to satisfy decoupling purposes. Finally, we analyse how different MPC parameters influence its performance to give some leads on how to use it to reduce loops interactions effectively.

The remaining part of the paper is organized as follows. In Sections II-III, a classical and MPC approach to control MIMO plants is presented. In section IV, it is discussed how to use MPC controller to realize dynamic decoupling objectives. Pros and cons of both methods are discussed and presented in a series of simulations of a selected TITO plant in Section V. The paper ends with conclusions and some final remarks.

\section{Classical ApProach to Decoupling}

Decentralized control is a typical approach to control a MIMO dynamic system. It means that the MIMO system is treated like a set of few Single Input Single Output (SISO) systems, which are easier to analyse and tune. Interactions between such SISO systems are usually neglected and treated as a disturbance. An example of such control scheme for a TITO plant is presented in Fig. 1. What can be done to 
minimize coupling effects, is the appropriate pairing of the plant inputs and outputs. To do that, one can use several interaction measuring methods. The most popular is the Relative Gain Array (RGA) [29] and its further modifications, such as Effective Relative Gain Array (ERGA), Dynamic Relative Gain Array (DRGA), NonSquare Relative Gain Array (NSRGA), and Nonlinear Relative Gain Array (NRGA) [30]. Apart from RGA, there are Hankel Interaction Index Array (HIIA) also [31], Participation Matrix (PM) [32], and so on.

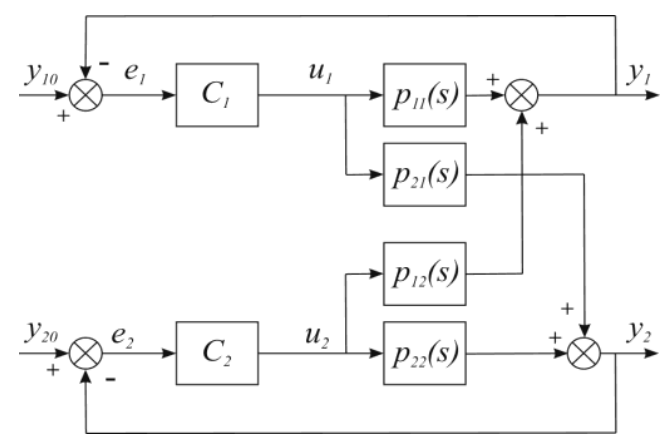

Fig. 1. Typical control scheme for a TITO plant.

In case of TITO plants, the perfect decoupling seems to be quite easy to solve by using some easy-to-calculate precompensators. Using the control scheme shown in Fig. 2, called inverted decoupling, a perfect decoupling is achieved by using pre-compensator with:

$$
\begin{aligned}
& d_{12}(s)=\frac{-p_{12}(s)}{p_{11}(s)}, \\
& d_{21}(s)=\frac{-p_{21}(s)}{p_{22}(s)} .
\end{aligned}
$$

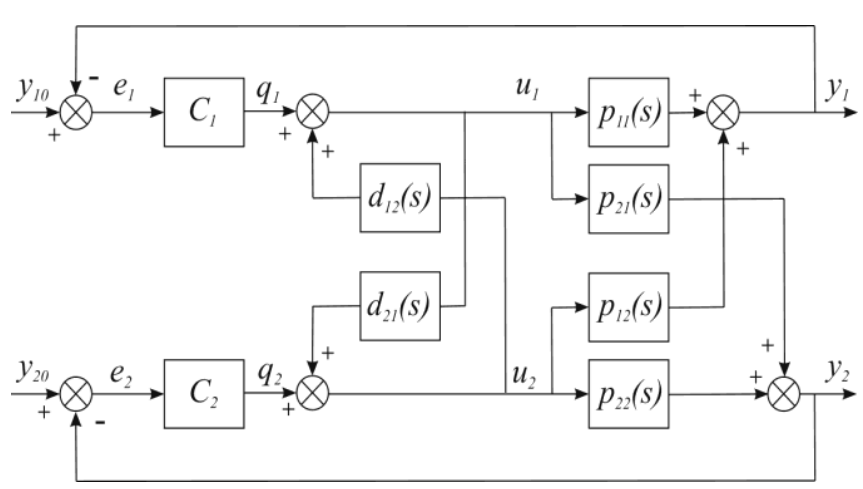

Fig. 2. Control scheme of the TITO plant with inverted decoupling.

In case of plants with more inputs and outputs, finding a decoupling controller or schemes like in Fig. 2 is much more complicated and usually needs more advanced techniques. Additionally, we have to remember that the above methods are quite easy to implement for square plants i.e., plants with the same number of inputs and outputs. In case of the right or left invertible plants with more inputs or outputs, respectively, we cannot divide the system into several separated SISO control loops. In such cases either a dedicated dynamic decoupling technique or MPC algorithms may be used.

\section{MPC ALGORITHM}

The MPC controller task is to calculate the future control actions at each sampling instant in order to minimize the cost function specified on the prediction $N$ and control $N_{u}$ horizon

$$
\begin{aligned}
\min _{\substack{\Delta U(t)_{\rightarrow} \\
\mathrm{E}^{\min }(t)_{\rightarrow}}} J(t) & =\left\{\left\|Y^{r}(t)_{\rightarrow}-Y^{p}(t)_{\rightarrow}\right\|_{M}^{2}+\left\|\Delta U(t)_{\rightarrow}\right\|_{L}^{2}+\right. \\
& \begin{array}{c}
\mathrm{E}^{\max }(t)_{\rightarrow} \\
\end{array} \\
& \left.+\rho^{\min }\left\|\mathrm{E}^{\min }(t)_{\rightarrow}\right\|^{2}+\rho^{\max }\left\|\mathrm{E}^{\max }(t)_{\rightarrow}\right\|^{2}\right\},
\end{aligned}
$$

where $\|V\|_{W}^{2}=V^{T} W V$ denotes the quadratic norm with weight matrix $\boldsymbol{W} \geq 0$ of the vector $\boldsymbol{V}$,

$$
Y^{r}(t)_{\rightarrow}=\left\lfloor\begin{array}{c}
y^{r}(t+1 \mid t) \\
\vdots \\
y^{r}(t+N \mid t)
\end{array}\right\rfloor \in \mathbb{R}^{N \times p}
$$

denotes the reference trajectory vector,

$$
Y^{p}(t)_{\rightarrow}=\left[\begin{array}{c}
y^{p}(t+1 \mid t) \\
\vdots \\
y^{p}(t+N \mid t)
\end{array}\right\rfloor \in \mathbb{R}^{N \times p}
$$

is the output prediction vector,

$$
\Delta U(t)_{\rightarrow}=\left[\begin{array}{c}
\Delta u(t \mid t) \\
\vdots \\
\Delta u\left(t+N_{u}-1 \mid t\right)
\end{array}\right\rfloor \in \mathbb{R}^{N_{u} \times m}
$$

is the vector of the future sequence of manipulated variable increments $\Delta u(t+j \mid t)$ subject to hard constraints imposed on the magnitude of the manipulated variables and its increments:

$$
\begin{gathered}
u^{\min } \leq u(t+j \mid t) \leq u^{\max }, \quad j=0,1,2, \ldots, N_{u}-1, \\
\Delta u^{\min } \leq \Delta u(t+j \mid t) \leq \Delta u^{\max }, \quad j=0,1,2, \ldots, N_{u}-1,
\end{gathered}
$$

as well as constraints imposed on predicted output variables:

$$
\begin{aligned}
& y^{\min }-\varepsilon^{\min }(t+j \mid t) \leq y^{p}(t+j \mid t) \leq y^{\max }+\varepsilon^{\max }(t+j \mid t), \\
& j=1,2, \ldots, N .
\end{aligned}
$$

Vectors:

$$
\begin{aligned}
& \mathrm{E}^{\min }(t)_{\rightarrow}=\left|\begin{array}{c}
\varepsilon^{\min }(t+1 \mid t) \\
\vdots \\
\varepsilon^{\min }(t+\mathrm{N} \mid t)
\end{array}\right| \in \mathbb{R}^{N \times p}, \\
& \mathrm{E}^{\max }(t)_{\rightarrow}=\left\lfloor\begin{array}{c}
\varepsilon^{\max }(t+1 \mid t) \\
\vdots \\
\varepsilon^{\max }(t+\mathrm{N} \mid t)
\end{array}\right\rfloor \in \mathbb{R}^{N \times p}
\end{aligned}
$$

determine the degree of constraint violation in case the criterion (3) is not solvable. As typically for the predictive controllers the actual control signals are used only and the computation is repeated in the next control step. 
For a LTI plant, the optimization problem (3) becomes the quadratic programming task, which has to be solved at each sampling time. It is now possible to do it efficiently in practice by using available solvers [33].

\section{DyNAMiC DeCOUPLing With THE USE OF MPC}

\section{A. Reference Signal Change}

Unlike a stepwise change in the classical control systems a typical way of changing set points in MPC is to shape them. Using filters and slowing down set point changes allows us to change the outputs more smoothly without large increase of control signals (8). Such method is proposed in [25] and [26]. However, it is not a dedicated decoupling method. It can also be used in classical control systems, so we will not consider it in our analysis.

\section{B. Adjusting Weighting Factors}

The weight matrices in cost function (3) in many practical applications of predictive control are taken most commonly in the form $M=I_{p \cdot N}$ or $M=0_{p \cdot N}, L=\lambda \cdot I_{m \cdot N_{u}}, \lambda>0$, $\rho^{\min }, \rho^{\max }>0$. There is the same weighting factor $\lambda$ for each plant input and output. As a result, all outputs are treated equally. However, we can introduce different weights for plant outputs $M=\mu_{i} I_{p \cdot N}, i=1,2, \ldots, p$ and inputs $L=\lambda_{j} \cdot I_{m \cdot N_{u}}, j=1,2, \ldots, m$. For the decoupling purposes, changing $\mu_{i}$ while keeping $\lambda_{j}$ constant allows us to separate some specific outputs and consequently obtain a significant reduction of the coupling effects. Decreasing $\mu_{i}$ for a specific output and/or increasing the rest of them "allows" to significantly reduce their change.

It seems that the simplest and the best way of changing these factors is its manual change at the moments of changing of the set points and bringing them back to the initial values $\mu$ after the transient or at least before the next set point change. In [20], $\mu_{i}$ values decrease exponentially. It is possible only if we know, in advance, the schedule of the reference signal changing.

In [25] and [26], $\mu_{i}$ are dependent on the control error and are given by

$$
\mu_{i}=\frac{\mu_{i, \max }}{1+\left|e_{i}(k)\right| \mu_{i, \text { damp }}},
$$

where $\mu_{i, \max }$ and $\mu_{i, \text { damp }}$ were assumed after some trial and error simulations. However, such algorithm may not work effectively when reference signal filters are applied (see section IV, subsection A) as the ratio between each $\mu_{i}$ may be too small to significantly change criterion (3) and to dump loop interactions.

\section{Adjusting Output Constraints}

Similar to the weighting factors the typical way of calculating the cost function (3) assumes constant values for minimal and maximal values of plant output. Practically, taking into consideration the standards of measuring devices, the same value as plant gains are scaled to standards. However, these constraints may be assumed and changed separately at the moments of changing some set points. $y_{i}^{\min }$ and $y_{i}^{\max }$ for $i=1,2, \ldots, p$ may be specified as for example, $\pm 2 \%$ of the appropriate set point. In case that such constraint is not able to satisfy it is naturally softened by (10) and (11) taken into consideration in (9). There are several advantages of this method. Firstly, it is more intuitive and straightforward. Secondly, problems with changing weight values may be avoided. And finally, it does not exclude adjusting weighting factors and shaping reference signals.

\section{EXAMPLE}

As an example to show the effects of the discussed control methods, we consider the distillation column model [34]

$$
\boldsymbol{P}(s)=\left|\begin{array}{cc}
\frac{12.8 e^{-s}}{16.7 s+1} & \frac{-18.9 e^{-3 s}}{21 s+1} \\
\frac{6.6 e^{-7 s}}{10.9 s+1} & \frac{-19.4 e^{-3 s}}{14.4 s+1}
\end{array}\right|
$$

It is a well-known model in literature, for which there are a lot of proposals of different control systems. Thus, it may be used as a reference one. In order to compare the control efficiency of this plant, six classical controllers have been taken from literature [1], [2], [4], [35]-[37]. In [1], [35][37], a distributed control scheme, as shown in Fig. 1, has been used while in works [2] and [4] a dynamic decoupling controller have been adopted. Work [2] proposes authors' version of the decoupling controller, whereas in [4] we find a classical control scheme with inverted decoupling (Fig. 2) with the decoupler taken as:

$$
\begin{aligned}
& d_{12}(s)=\frac{18.9(16.7 s+1) e^{-2 s}}{12.8(21 s+1)} \\
& d_{21}(s)=\frac{6.6(14.4 s+1) e^{-4 s}}{19.4(10.9 s+1)}
\end{aligned}
$$

It has been taken only to compare results obtained by the ideal decoupling with other control schemes.

We have assumed the following simulation scenario. At the beginning, the set point of first output $y_{1}$ is changed from 0 to 1 . After 80 seconds, the next set point is changed from 0 to 0.5 . Results of simulations are presented in Figures 3-6.

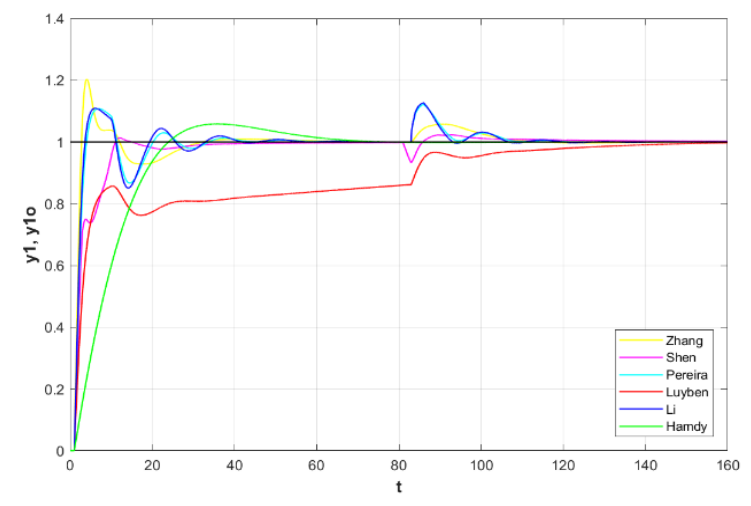

Fig. 3. Change of the first output for different PID controllers. 


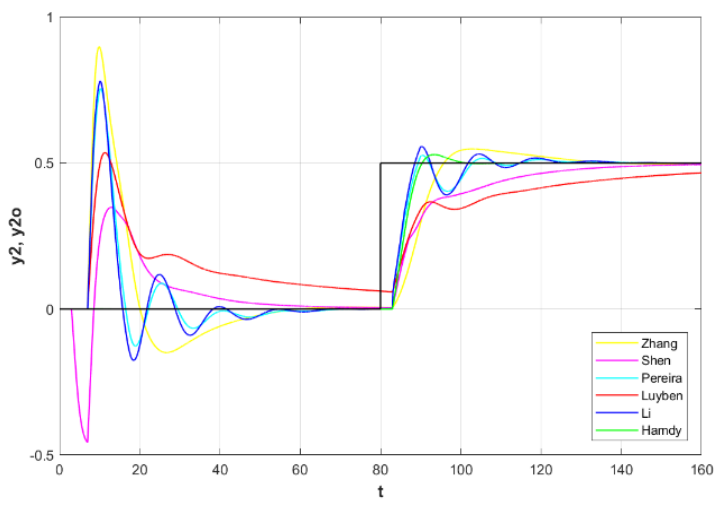

Fig. 4. Change of the second output for different PID controllers.

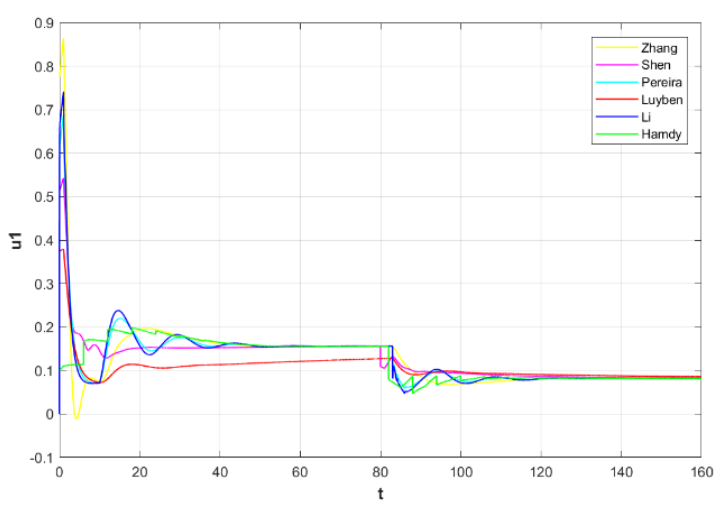

Fig. 5. Change of the first input for different PID controllers.

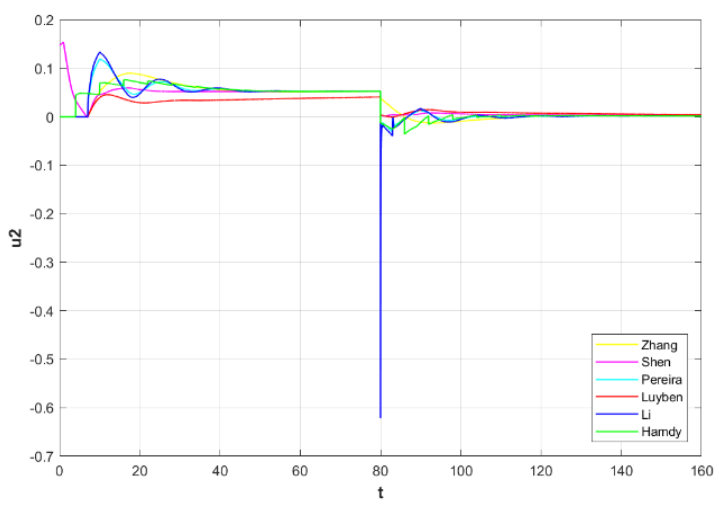

Fig. 6. Change of the second input for different PID controllers.

Classical controllers have been compared with different MPC controllers, tuned by changing weights or output constraints. To verify, how other parameters of the criterion (3) influence the control results, we have checked these MPC controllers with different prediction and control horizons equal to $N=5,10,20,30$ and $N_{u}=2,3,5,10$ sampling times, respectively. The plant model (13) has been discretized with the sampling time equal to 1 second.

To check the decoupling abilities of the MPC controller, all simulations have been carried out by both adjusting the weighting factors and output constraints. Value of $\mu_{1}$ is equal to 1 for the first 80 seconds and 10 afterwards. Similarly $\mu_{2}$ starts with a value of 10 and is changed to 1 at 80 seconds. The constraints imposed on the plant outputs are as follows: $y_{1}^{\min }=0.98, y_{1}^{\max }=1.02$ and $y_{2}^{\min }=0.49$, $y_{2}^{\max }=0.51$. Results of simulations for the selected MPC controllers are presented in Figs. 7-10.

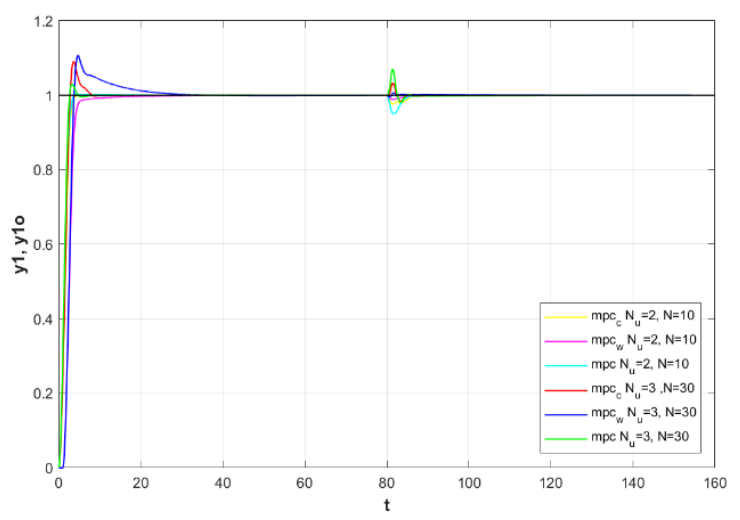

Fig. 7. Change of the first output for different MPC controllers.

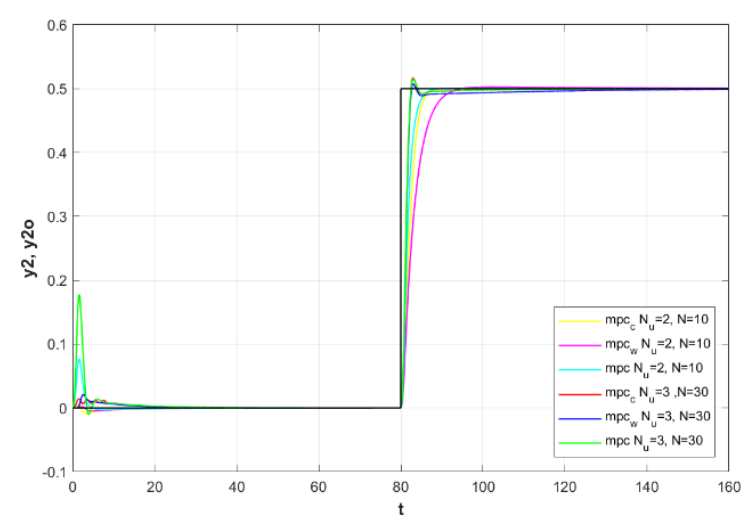

Fig. 8. Change of the second output for different MPC controllers.

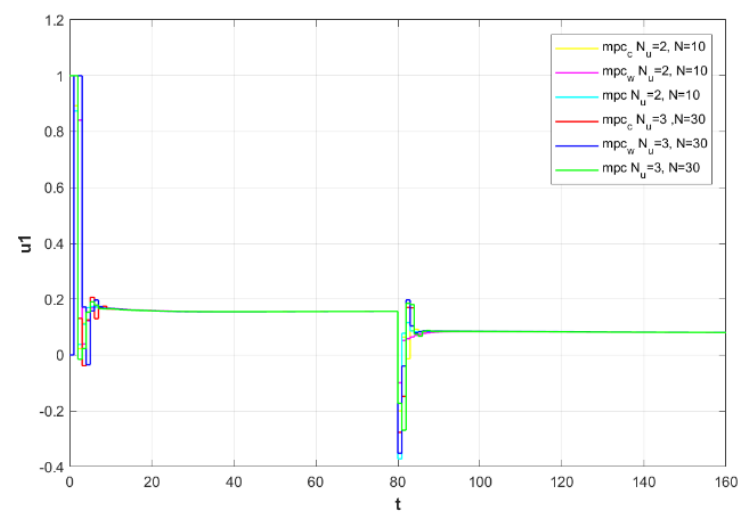

Fig. 9. Change of the first input for different MPC controllers.

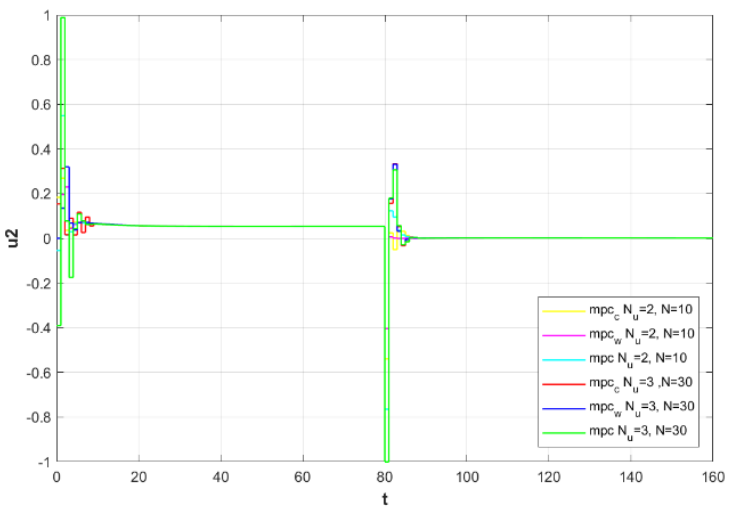

Fig. 10. Change of the second input for different MPC controllers. 
TABLE I. PERFORMANCE INDICES FOR PID CONTROLLER.

\begin{tabular}{|c|c|c|c|c|c|c|c|c|c|c|c|c|}
\hline PID & ISE1 & ISE2 & $t_{r 1}$ & $t_{r 2}$ & $y_{1}^{\max }$ & $y_{1}^{\min }$ & $y_{2}^{\max }$ & $y_{2}^{\min }$ & $u_{1}^{\max }$ & $u_{1}^{\min }$ & $u_{2}^{\max }$ & $u_{2}^{\min }$ \\
\hline Hamdy & 0.0000 & 0.0000 & 22.4700 & 10.0000 & 1.0000 & 0.9986 & 0.0006 & -0.0001 & 0.1984 & 0.0470 & 0.0765 & -0.0356 \\
\hline Li & 0.0733 & 2.4975 & 3.5200 & 8.3800 & 1.1277 & 0.9956 & 0.7814 & -0.1757 & 0.7413 & 0.0000 & 0.1339 & -0.6217 \\
\hline Luyben & 0.1356 & 2.7718 & 121.1200 & - & 0.9976 & 0.8591 & 0.5354 & 0.0000 & 0.3795 & 0.0721 & 0.0456 & -0.0009 \\
\hline Pereira & 0.0724 & 2.4126 & 3.8600 & 9.1300 & 1.1229 & 0.9991 & 0.7545 & -0.1266 & 0.6888 & 0.0000 & 0.1194 & -0.5653 \\
\hline Shen & 0.0141 & 1.6171 & 10.5200 & 64.5000 & 1.0228 & 0.9324 & 0.3483 & -0.4573 & 0.5430 & 0.0821 & 0.1537 & -0.0017 \\
\hline Zhang & 0.0374 & 4.2169 & 2.7500 & 15.3200 & 1.0577 & 0.9974 & 0.8978 & -0.1492 & 0.8643 & -0.0116 & 0.0898 & -0.0127 \\
\hline
\end{tabular}

TABLE II. PERFORMANCE INDICES FOR MPC WITH OUTPUT CONSTRAINTS.

\begin{tabular}{|c|c|c|c|c|c|c|c|c|c|c|c|c|}
\hline MPC $_{\text {constr_y }}$ & ISE1 & ISE2 & $t_{r 1}$ & $t_{r 2}$ & $y_{1}^{\max }$ & $y_{1}^{\min }$ & $y_{2}^{\max }$ & $y_{2}^{\min }$ & $u_{1}^{\max }$ & $u_{1}^{\min }$ & $u_{2}^{\max }$ & $u_{2}^{\min }$ \\
\hline $\mathrm{N}_{\mathrm{u}}=2, \mathrm{~N}=5$ & .0009 & 0.0001 & 2.8600 & 2.8700 & 1.0010 & 0.9785 & 0.0090 & -0.0064 & 1.0000 & -0.3988 & 0.2607 & -0.9528 \\
\hline $\mathrm{N}_{\mathrm{u}}=2, \mathrm{~N}=10$ & 0.0017 & 0.0003 & 3.3900 & 6.3000 & 1.0004 & 0.9760 & 0.0052 & -0.0097 & 1.0000 & -0.2005 & 0.2696 & -0.5399 \\
\hline $\mathrm{N}_{\mathrm{u}}=2, \mathrm{~N}=20$ & 0.0022 & 0.0016 & 8.2800 & 8.2900 & 1.0021 & 0.9770 & 0.0036 & -0.0103 & 1.0000 & -0.1282 & 0.1929 & -0.4025 \\
\hline $\mathrm{N}_{\mathrm{u}}=2, \mathrm{~N}=30$ & 0.0027 & 0.0024 & 15.2800 & 8.5200 & 1.0046 & 0.9772 & 0.0001 & -0.0105 & 1.0000 & -0.1169 & 0.2033 & -0.3821 \\
\hline $\mathrm{N}_{\mathrm{u}}=3, \mathrm{~N}=10$ & 0.0012 & 0.0004 & 2.7900 & 2.3000 & 1.0335 & 0.9861 & 0.0147 & -0.0111 & 1.0000 & -0.2765 & 0.3476 & -1.0000 \\
\hline $\mathrm{N}_{\mathrm{u}}=3, \mathrm{~N}=20$ & 0.0012 & 0.0004 & 2.7900 & 2.3400 & 1.0332 & 0.9850 & 0.0148 & -0.0024 & 1.0000 & -0.2767 & 0.3412 & -1.0000 \\
\hline $\mathrm{N}_{\mathrm{u}}=3, \mathrm{~N}=30$ & 0.0012 & 0.0012 & 2.6900 & 2.3800 & 1.0328 & 0.9838 & 0.0144 & 0.0000 & 1.0000 & -0.2769 & 0.3342 & -1.0000 \\
\hline $\mathrm{N}_{\mathrm{u}}=5, \mathrm{~N}=10$ & 0.0011 & 0.0004 & 2.7900 & 2.2600 & 1.0334 & 0.9881 & 0.0147 & -0.0107 & 1.0000 & -0.2765 & 0.3603 & -1.0000 \\
\hline $\mathrm{N}_{\mathrm{u}}=5, \mathrm{~N}=20$ & 0.0011 & 0.0004 & 2.7900 & 2.2600 & 1.0334 & 0.9881 & 0.0147 & -0.0111 & 1.0000 & -0.2765 & 0.3602 & -1.0000 \\
\hline $\mathrm{N}_{\mathrm{u}}=5, \mathrm{~N}=30$ & 0.0011 & 0.0004 & 2.7800 & 2.2600 & 1.0334 & 0.9882 & 0.0147 & -0.0118 & 1.0000 & -0.2765 & 0.3603 & -1.0000 \\
\hline $\mathrm{N}_{\mathrm{u}}=10, \mathrm{~N}=10$ & 0.0011 & 0.0004 & 2.7900 & 2.2600 & 1.0334 & 0.9881 & 0.0147 & -0.0106 & 1.0000 & -0.2765 & 0.3617 & -1.0000 \\
\hline $\mathrm{N}_{\mathrm{u}}=10, \mathrm{~N}=20$ & 0.0011 & 0.0004 & 2.7900 & 2.2600 & 1.0334 & 0.9881 & 0.0147 & -0.0106 & 1.0000 & -0.2765 & 0.3617 & -1.0000 \\
\hline $\mathrm{N}_{\mathrm{u}}=10, \mathrm{~N}=30$ & 0.0011 & 0.0004 & 2.7900 & 2.2600 & 1.0334 & 0.9881 & 0.0147 & -0.0106 & 1.0000 & -0.2765 & 0.3617 & -1.0000 \\
\hline
\end{tabular}

TABLE III. PERFORMANCE INDICES FOR MPC WITH CHANGED WEIGHTS.

\begin{tabular}{|c|c|c|c|c|c|c|c|c|c|c|c|c|}
\hline MPC $_{\text {weights }}$ & ISE1 & ISE2 & $t_{r 1}$ & $t_{r 2}$ & $y_{1}^{\max }$ & $y_{1}^{\min }$ & $y_{2}^{\max }$ & $y_{2}^{\min }$ & $u_{1}^{\max }$ & $u_{1}^{\min }$ & $u_{2}^{\max }$ & $u_{2}^{\min }$ \\
\hline $\mathrm{N}_{\mathrm{u}}=2, \mathrm{~N}=5$ & 0.0002 & 0.0000 & 3.8900 & 6.0700 & 1.0009 & 0.9887 & 0.0028 & -0.0012 & 1.0000 & -0.2439 & 0.2586 & -0.6916 \\
\hline $\mathrm{N}_{\mathrm{u}}=2, \mathrm{~N}=10$ & 0.0003 & 0.0002 & 4.8900 & 10.9000 & 1.0001 & 0.9890 & 0.0021 & -0.0049 & 1.0000 & -0.0991 & 0.2301 & -0.4044 \\
\hline $\mathrm{N}_{\mathrm{u}}=2, \mathrm{~N}=20$ & 0.0005 & 0.0013 & 24.2500 & 12.1100 & 1.0001 & 0.9874 & 0.0005 & -0.0120 & 1.0000 & -0.0517 & 0.2017 & -0.3052 \\
\hline $\mathrm{N}_{\mathrm{u}}=2, \mathrm{~N}=30$ & 0.0010 & 0.0020 & 34.0700 & 10.7700 & 1.0000 & 0.9838 & 0.0001 & -0.0139 & 1.0000 & -0.0562 & 0.2117 & -0.3001 \\
\hline $\mathrm{N}_{\mathrm{u}}=3, \mathrm{~N}=10$ & 0.0000 & 0.0001 & 3.7900 & 2.3500 & 1.0055 & 0.9948 & 0.0076 & 0.0000 & 1.0000 & -0.3519 & 0.3472 & -1.0000 \\
\hline $\mathrm{N}_{\mathrm{u}}=3, \mathrm{~N}=20$ & 0.0000 & 0.0006 & 3.7200 & 2.4300 & 1.0051 & 0.9945 & 0.0162 & -0.0000 & 1.0000 & -0.3547 & 0.3368 & -1.0000 \\
\hline $\mathrm{N}_{\mathrm{u}}=3, \mathrm{~N}=30$ & 0.0001 & 0.0011 & 3.6500 & 2.4800 & 1.0065 & 0.9949 & 0.0210 & -0.0001 & 1.0000 & -0.3516 & 0.3311 & -1.0000 \\
\hline $\mathrm{N}_{\mathrm{u}}=5, \mathrm{~N}=10$ & 0.0000 & 0.0000 & 3.7900 & 2.3100 & 1.0066 & 0.9955 & 0.0057 & -0.0004 & 1.0000 & -0.3478 & 0.3286 & -1.0000 \\
\hline $\mathrm{N}_{\mathrm{u}}=5, \mathrm{~N}=20$ & 0.0000 & 0.0001 & 3.7900 & 2.3100 & 1.0069 & 0.9956 & 0.0074 & -0.0000 & 1.0000 & -0.3472 & 0.3291 & -1.0000 \\
\hline $\mathrm{N}_{\mathrm{u}}=5, \mathrm{~N}=30$ & 0.0000 & 0.0001 & 3.7700 & 2.3000 & 1.0073 & 0.9957 & 0.0087 & -0.0000 & 1.0000 & -0.3460 & 0.3298 & -1.0000 \\
\hline $\mathrm{N}_{\mathrm{u}}=10, \mathrm{~N}=10$ & 0.0000 & 0.0000 & 3.7900 & 2.3100 & 1.0070 & 0.9956 & 0.0057 & -0.0007 & 1.0000 & -0.3465 & 0.3277 & -1.0000 \\
\hline $\mathrm{N}_{\mathrm{u}}=10, \mathrm{~N}=20$ & 0.0000 & 0.0000 & 3.7900 & 2.3100 & 1.0070 & 0.9956 & 0.0056 & -0.0007 & 1.0000 & -0.3466 & 0.3277 & -1.0000 \\
\hline $\mathrm{N}_{\mathrm{u}}=10, \mathrm{~N}=30$ & 0.0000 & 0.0000 & 3.7900 & 2.3100 & 1.0069 & 0.9956 & 0.0055 & -0.0008 & 1.0000 & -0.3466 & 0.3278 & -1.0000 \\
\hline
\end{tabular}

Controllers with changed weighting factors are marked by ' $\mathrm{mpc}_{\mathrm{w}}$ ', output constraints by ' $\mathrm{mpc}_{\mathrm{c}}$ ', and those without any change of weighting factors and output constraints by "mpc".

To compare the described different control strategies some important performance indices have been analysed. These are Integral Squared Error (ISE), rise time $t_{r}$, and maximal and minimal values of input and output signals. All of them are analysed separately for the first and second output and input $\left(u_{1}, u_{2}\right)$ signals. For $y_{1}$ ISE was calculated for the time period from 80 to $160 \mathrm{~s}$ after the change of the reference signal for the second output, and for $y_{2}$ - from 0 to $80 \mathrm{~s}$ after the change of the reference signal for the first output. Rise time is considered as the time taken by a signal $-y_{1}$ or $y_{2}$ to change from 0 to $98 \%$ of its final value. $y_{i}^{\min }$ and $y_{i}^{\max }$ have also been checked in the time periods: from 0 to $80 \mathrm{~s}$ and from 80 to $160 \mathrm{~s}$ for the $y_{2}$ and $y_{1}$, respectively. Data sheet with all calculated indices is presented in Tables I-III.

As we can see in the figures and after analysing data in Tables I-III, it is observed that MPC meets control objectives and outperforms PID controllers. Even pure MPC, without any change of weighting factors and output constraints, which does not satisfy the decoupling objectives, gives better results than standard PID controllers.

\section{CONCLUSIONS}

Though the control objective for the MPC is to minimize criterion like (3), it does not guarantee perfect decoupling. We may only try to reduce the input-output interactions by 
modifications of the criterion parameters, weighting factors and constraints. Fortunately, the criterion is calculated at each sampling instant, so modifications of weights and output constraints may be easily implemented. These properties of MPC may be very useful for dynamic decoupling of the nonlinear MIMO plants which may still be treated like an open question. In [38], [39] two, nonlinear model predictive controllers are analysed. In the first one, the model is successively linearized on-line for the current operating conditions. In the second algorithm, the predicted output trajectory of the system is linearized along the trajectory of the future control scenario. In both cases, linearization makes it possible to obtain quadratic optimization of MPC problems and make the algorithms computationally efficient. So, it seems that these methods could be easily adopted and used for dynamic decoupling purposes of nonlinear MIMO plants.

\section{REFERENCES}

[1] R. D. O. Pereira, M. Veronesi, A. Visioli, J. E. Normey-Rico, "Implementation and test of a new autotuning method for PID controllers of TITO processes", Control Engineering Practice, vol. 58, pp. 171-185, 2017. DOI: 10.1016/j.conengprac.2016.10.010.

[2] Y. Shen, W. J. Cai, S. Li, "Multivariable process control: decentralized, decoupling, or sparse", Ind. Eng. Chem. Res., vol. 49 no. 2, pp. 761-771, 2010. DOI: 10.1021/ie901453z.

[3] M. Hamdy, A. Ramadan, "Design of Smith predictor and fuzzy decoupling for MIMO chemical processes with time delays", Asian Journal of Control, vol. 19, no. 1, pp. 57-66, 2017. DOI: 10.1002/asjc.1338.

[4] M. Hamdy, A. Ramadan, B. Abozalam, "Comparative study of different decoupling schemes for for TITO binary distillation column via PI controller", IEEE/CAA Journal of Automatica Sinica, vol. 5, no. 4, pp. 869-877, 2018.

[5] Ch-S. Chiu, "A dynamic decoupling approach to robust T-S fuzzy model-based control", IEEE Transactions on Fuzzy Systems, vol. 22, no. 5, pp. 1088-1100, 2014. DOI: 10.1109/TFUZZ.2013.2280145.

[6] K. H. Park, G. H. Choi, "Necessary and Sufficient Conditions for the Existence of Decoupling Controllers in the Generalized Plant Model", Journal of Electrical Engineering and Technology, vol. 6, pp. 706712, 2011. DOI: 10.5370/JEET.2011.6.5.706

[7] K. H. Park, "Parameterization of decoupling controllers in the Generalized Plant Model", IEEE Trans. Automat. Contr., vol. 57, no. 4, pp. 1067-1070, 2012. DOI: 10.1109/TAC.2011.2173410.

[8] K. H. Park, "A simple existence condition of one-degree-of-freedom block decoupling controllers", Automatica, vol. 51, pp. 14-17, 2015 DOI: 10.1016/j.automatica.2014.10.072.

[9] V. Kucera, "Optimal decoupling controllers revisited", Control and Cybernetics, vol. 42, no. 1, pp. 139-154, 2013.

[10] R. Galindo, "Input/output decoupling of square linear systems by dynamic two-parameter stabilizing control", Asian Journal of Control, vol. 18, no. 6, pp. 2310-2316, 2016. DOI: 10.1002/asjc. 1285 .

[11] M. B. Hariz, F. Bouani, "Synthesis and implementation of a robust fixed low-order controller for uncertain systems", Arabian Journal for Science and Engineering, vol. 41, no. 9, pp. 3645-3654, 2016. DOI: 10.1007/s13369-016-2247-7.

[12] S. Banka, P. Dworak, "Efficient algorithm for designing multipurpose control systems for invertible and right invertible MIMO plants", Bulletin of the Polish Academy of Sciences, vol. 54, no. 4, pp. 429436, 2006.

[13] P. Dworak, "Squaring down plant model and I/O grouping strategies for a dynamic decoupling of left-invertible MIMO plants", Bulletin of the Polish Academy of Sciences, vol. 62, no. 3, pp. 471-479, 2014. DOI: $10.2478 /$ bpasts-2014-0050.

[14] P. Dworak, "Dynamic decoupling of left-invertible MIMO LTI plants", Archives of Control Science, vol. 21, pp. 443-459, 2011. DOI: 10.2478/v10170-011-0006-2.

[15] S. Banka, P. Dworak, K. Jaroszewski, "Linear adaptive structure for control of a nonlinear MIMO dynamic plant", Int. Journal of Applied Mathematics and Computer Science, vol. 23, no. 1, pp. 47-63, 2013. DOI: 10.2478/amcs-2013-0005.

[16] P. Dworak, "A type of fuzzy T-S controller for a nonlinear MIMO dynamic plant", Elektronika ir Elektrotechnika, vol. 20, no 5, pp. 8-
14, 2014. DOI: 10.5755/j01.eee.20.5.7091.

[17] P. Dworak, K. Pietrusewicz, S. Domek, "Improving stability and regulation quality of nonlinear MIMO processes", in Proc. of Methods and Models in Automation and Robotics, Międzyzdroje, Poland, vol. 14, pp. 180-185, 2009.

[18] S. Banka, P. Dworak, K. Jaroszewski, "Design of a multivariable neural controller for control of a nonlinear MIMO plant", International Journal of Applied Mathematics and Computer Science, vol. 24, no. 2, pp. 357-369, 2014. DOI: 10.2478/amcs-2014-0027.

[19] G. Liu, Z. Wang, C. Mei, Y. Ding, "A review of decoupling control based on multiple models", in 24th Chinese Control and Decision Conference, 2012, pp. 1077-1081. DOI: 10.1109/CCDC.2012.6244171.

[20] O. Bego, N. Peric, I. Petrovic, „Decoupling multivariable GPC with reference observation", in 10th Mediterranean Electromechanical Conference, 2000, vol. II, pp. 819-822. DOI: 10.1109/MELCON.2000.880059.

[21] F. Arousi, "Predictive control algorithms for linear and nonlinear processes", PhD. Thesis, Budapest, Hungary, 2009.

[22] R. Haber, R. Bars, U. Schmitz, Predictive control in process engineering. Weinheim, WILEY-VCH, 2011. DOI $10.1002 / 9783527636242$.

[23] S. Oblak, I. Skrjanc, "Multivariable fuzzy predictive functional contorl of a MIMO nonlinear system", IEEE International Symposium on Intelligent Control, Limassol, Cyprus, pp. 1029-1034, 2005. DOI: $10.1109 / .2005 .1467155$.

[24] A.Saniye, K.Suleyman, "Decoupling constrained model predictive control of multi-component packed distillation column" World Applied Science Journal, vol. 13, no. 3, pp. 517-530, 2011.

[25] U. Schmitz, R. Haber, F. Arousi, R. Bars, "Decoupling predictive control by error dependent tuning of the weighting factors", Process Control Conference, 2007, pp. 131-140.

[26] K. Zabet, R. Haber, "Improvement of the decoupling effect of the predictive controller GPC and PFC by parameter adaptation", in Proc. $18^{\text {th }}$ Interantional Conference on Process Control, Tatranska Lomnica, Slovakia, 2011, pp. 419-426.

[27] M. A. Zermani, E. Feki, A. Mami, "Self-tuning weighting factor to decoupling control for incubator system", Int. Journal of information Technology, control and Automation, vol. 2, no. 3, pp. 67-83, 2012.

[28] M. Petrov, S. Ahmed, A. Ichtev, A. Taneva, "Fuzzy-neural Model Predictive Control of multivariable processes", Chapter in Advanced Model Predictive Control, Edited by Tao Zheng, DOI: $10.5772 / 16828$.

[29] E. H. Bristol, "On a new measure of interaction for multivariable process control", IEEE Trans. Automatic Control, AC-11, pp. 133134, 1966. DOI: 10.1109/TAC.1966.1098266.

[30] A. Khaki-Sedigh, B. Moaveni, Control configuration selection for multivariable plants, Springer, Berlin, 2009. DOI: 10.1007/978-3642-03193-9.

[31] B. Wittenmark, M.E. Salgado, "Hankel-norm based interaction measure for input-output pairing", in Proc. 15th Triennial World Congress, CD-ROM, 2002. DOI: 10.3182/20020721-6-ES1901.01625 .

[32] M. E. Salgado, A. Conley, "MIMO interaction measure and controller structure selection", Int. J. Control, vol. 77, no. 4, pp. 367-383, 2007. DOI: $10.1080 / 0020717042000197631$.

[33] J. Nocedal, S. J. Wright, Numerical optimisation, Springer, Berlin, 2006.

[34] R. K. Wood, M. W. Berry, "Terminal composition control of a binary distillation column", Chemical Engineering Science, vol. 28, no. 16, pp. 1707-1710, 1973. DOI: 10.1016/0009-2509(73)80025-9.

[35] S. Y. Li, W-J. Cai, H. Mei, Q. Xiong, "Effective decentralized TITO process identification from closed-loop step responses", Asian Journal of Control, vol. 7, no. 2, pp. 154-162, 2005. DOI: 10.1111/j.1934-6093.2005.tb00384.x.

[36] W. L. Luyben, "Simple method for tuning SISO controllers in multivariable systems", Industrial and Engineering Chemistry Research, vol. 25, no. 3, pp. 654-658, 1986. DOI: 10.1021/i200034a010.

[37] Y. Zhang, Q.-G. Wang, K. J. Astrom, "Dominant pole placement for multi-loop control systems", Automatica, vol. 38, no. 7, pp. 12131220, 2002. DOI: 10.1016/S0005-1098(02)00009-2.

[38] M. Ławryńczuk, "Nonlinear predictive control of dynamic systems represented byWiener-Hammerstein models", Nonlinear Dynamics, vol. 86, no. 2, pp. 1193-1214, 2016. DOI: 10.1016/j.isatra.2014.09.018

[39] M. Ławryńczuk, "Nonlinear predictive control of a boiler-turbine unit: A state-space approach with successive on-line model linearisation and quadratic optimisation", ISA Transactions, vol. 67, pp. 476-495, 2017. DOI: 10.1016/j.isatra.2017.01.016. 